\title{
Responsiveness of glycogen breakdown to cyclic AMP in perfused liver from rats with insulin-induced hypoglycemia
}

M. Vardanega-Peicher ${ }^{1}$, R. Curi ${ }^{2}$, S. Pagliarini e Silva ${ }^{1}$ K.F. Nascimento ${ }^{1}$ and R.B. Bazotte ${ }^{1}$
${ }^{1}$ Departamento de Farmácia e Farmacologia, Universidade Estadual de Maringá, Maringá, PR, Brasil

2Departamento de Fisiologia e Biofísica, Universidade de São Paulo, São Paulo, SP, Brasil
Correspondence

R.B. Bazotte

Departamento de Farmácia e

Farmacologia

Universidade Estadual de Maringá

87020-900 Maringá, PR

Brasil

Fax: +55-44-263-6231

E-mail: rbbazotte@uem.br

Research supported by CNPq, CAPES and PRONEX (No. 168/97).

S. Pagliarini e Silva and

K.F. Nascimento are recipients

of CNPq fellowships.

Received December 17, 2001

Accepted September 4, 2002

\section{Introduction}

During insulin-induced hypoglycemia, hepatic glucose production must increase to match the energy demands of the brain. In the fed state, when liver glycogen stores are present, the hepatic response to insulininduced hypoglycemia operates primarily through glycogenolysis $(1,2)$ rather than gluconeogenesis (3). Furthermore, there is considerable evidence that during insulininduced hypoglycemia glucagon and epinephrine are important counter-regulatory hormones involved in the activation of glycogen breakdown $(4,5)$.
Recently we demonstrated (6) that the administration of insulin at pharmacological levels was capable of inhibiting isoproterenol-induced hepatic glycogen breakdown. Because the activation of hepatic glycogenolysis promoted by $\beta$-adrenergic agonists is mediated by adenosine-3'-5'-cyclic monophosphate (cAMP), we decided to investigate the participation of cAMP in this effect (6).

Since the cellular levels of cAMP and analogues are proportional to the extracellular concentration used in the liver perfusion experiments (7), it is possible to investigate the hepatic responsiveness of glycogen break- 
down to cAMP during insulin-induced hypoglycemia. For this purpose, we used in situ perfused liver. This technique has the advantage of determining metabolic rates on the basis of the composition of the perfusate in the intact organ $(8,9)$.

Furthermore, in order to obtain information about the participation of insulin in hepatic responsiveness to cAMP, additional experiments measuring the direct effect of insulin on glycogen catabolism promoted by cAMP and analogues were performed.

\section{Material and Methods}

Male Wistar fed rats (200-220 g) were employed. Insulin rats received an intraperitoneal (ip ) injection of $1 \mathrm{IU} / \mathrm{kg}$ of Neosulin ${ }^{\circledR}$ $\mathrm{R}$ (regular insulin obtained from Biobrás, Montes Claros, MG, Brazil). Control rats were injected with the same volume of saline. One hour after the administration of insulin or saline the rats were anesthetized ip with $40 \mathrm{mg} / \mathrm{kg}$ sodium pentobarbital. After laparotomy, blood was collected from the vena cava for the measurement of glucose (10) and insulin (11). As expected, insulin rats showed increased $(\mathrm{P}<0.05)$ insulinemia $(436.0 \pm 13.2 \mu \mathrm{IU} / \mathrm{ml}, \mathrm{N}=23)$ compared to control rats $(47.6 \pm 3.8 \mu \mathrm{IU} / \mathrm{ml}, \mathrm{N}=23)$ and decreased $(\mathrm{P}<0.05)$ glycemia $(42.1 \pm 2.0$ $\mathrm{mg} / \mathrm{dl}, \mathrm{N}=23$ ) compared to the control group $(139 \pm 2.4 \mathrm{mg} / \mathrm{dl}, \mathrm{N}=23)$. Since hypoglycemia was established $60 \mathrm{~min}$ after insulin injection, this period of time was chosen to carry out the first set of experiments with isolated perfused livers. Thus, 60 min after the administration of insulin or saline the rats were anesthetized ip with 40 $\mathrm{mg} / \mathrm{kg}$ sodium pentobarbital. After laparotomy, the livers were perfused as previously described $(6,8,9,12)$.

To determine the effect of cyclic nucleotides on glycogen catabolism, cAMP concentrations capable of producing about $50 \%$ (i.e., $3 \mu \mathrm{M}$ ) and $100 \%$ (i.e., $15 \mu \mathrm{M}$ ) of maximal glycogen catabolism were employed.
For N ${ }^{6}, 2^{\prime}$-O-dibutyryl-adenosine-3'-5'-cyclic monophosphate (DB-cAMP) the concentrations needed for 50 and $100 \%$ catabolism were 0.10 and $0.15 \mu \mathrm{M}$, respectively (results not shown). Therefore, after a pre-infusion period (10 min) livers from insulin and control rats were perfused for $20 \mathrm{~min}$ (10-30 min) with cAMP or DB-cAMP dissolved in the perfusion fluid followed by a post-infusion period $(20 \mathrm{~min})$ to allow a return to basal levels. Thus, the activation of glucose (10), L-lactate (13) and pyruvate (14) production was taken to be the difference between the rates of release of these compounds during (10-30 $\mathrm{min}$ ) and before (0-10 min) the infusion of cAMP or DB-cAMP. Glycogen catabolism was calculated to be the sum of glucose plus the half-sum of Llactate and pyruvate [glucose $+1 / 2$ (L-lactate + pyruvate)]. The release of these metabolites provides the rate of glycogenolysis because pyruvate oxidation, pentose-monophosphate shunt and recycling of pyruvate to glucose are minimal (15). All metabolic measurements are expressed as $\mu \mathrm{mol} \cdot \mathrm{min}^{-1} \cdot \mathrm{g}^{-1}$.

In the second set of experiments the direct effect of insulin on the kinetics of the activation of glycogen catabolism promoted by $3 \mu \mathrm{M}$ cAMP was investigated. Thus, after a pre-infusion period of $10 \mathrm{~min}$, livers from control rats were perfused for $15 \mathrm{~min}$ (10-25 min) with $3 \mu \mathrm{M}$ cAMP, followed by a combined infusion of $3 \mu \mathrm{M}$ cAMP and $500 \mu \mathrm{IU} /$ $\mathrm{ml}$ insulin for $10 \mathrm{~min}$ (25-35 $\mathrm{min}$ ). The concentration of insulin used was similar to that obtained for insulin rats $60 \mathrm{~min}$ after insulin administration. The effect of insulin on the activation of glycogen catabolism promoted by cAMP was measured as described above.

In the third set of experiments the direct effect of insulin $(500 \mu \mathrm{IU} / \mathrm{ml})$ on the activation of glycogen catabolism promoted by 3 and $15 \mu \mathrm{M}$ cAMP, 0.10 and $0.15 \mu \mathrm{M}$ DBcAMP, $3 \mu \mathrm{M}$ 8-bromo-adenosine-3'-5'cyclic monophosphate (8Br-cAMP) or $3 \mu \mathrm{M}$ $\mathrm{N}^{6}$-monobutyryladenosine-3'-5'-cyclic mono- 
phosphate (6MB-cAMP) was investigated. Thus, after a pre-infusion period of $10 \mathrm{~min}$, livers from control rats were perfused for 20 min (10-30 $\mathrm{min})$ with a combined infusion of insulin $(500 \mu \mathrm{IU} / \mathrm{ml})$ and a cyclic nucleotide (cAMP, DB-cAMP, 8Br-cAMP or 6MBcAMP) followed by a post-infusion period of 20 min to allow a return to basal levels. The activation of glycogen catabolism was measured as the difference between the rates of glycogenolysis during (10-30 $\mathrm{min}$ ) and before (0-10 $\mathrm{min})$ the infusion of the cyclic nucleotides.

The computer program GraphPad Prism (version 2.0) was used to calculate the area under the curve, expressed as $\mu \mathrm{mol} / \mathrm{g}$ liver fresh weight. Data were analyzed statisti- cally by the unpaired Student $t$-test. A 95\% level of confidence $(\mathrm{P}<0.05)$ was accepted for all comparisons. Results are reported as means \pm SEM.

\section{Results}

In the first set of experiments the effect of cAMP and DB-cAMP on glycogen catabolism in livers from control and insulin rats was compared. As shown in Figure 1, the infusion of cAMP or DB-cAMP promoted a rapid increase in hepatic glycogenolysis. However, the values obtained for cAMP (3 $\mu \mathrm{M})$ and DB-cAMP $(0.10 \mu \mathrm{M})$ were lower $(\mathrm{P}<0.05)$ in the insulin group (Figure 1A,C). In contrast, the increase of glycogenolysis
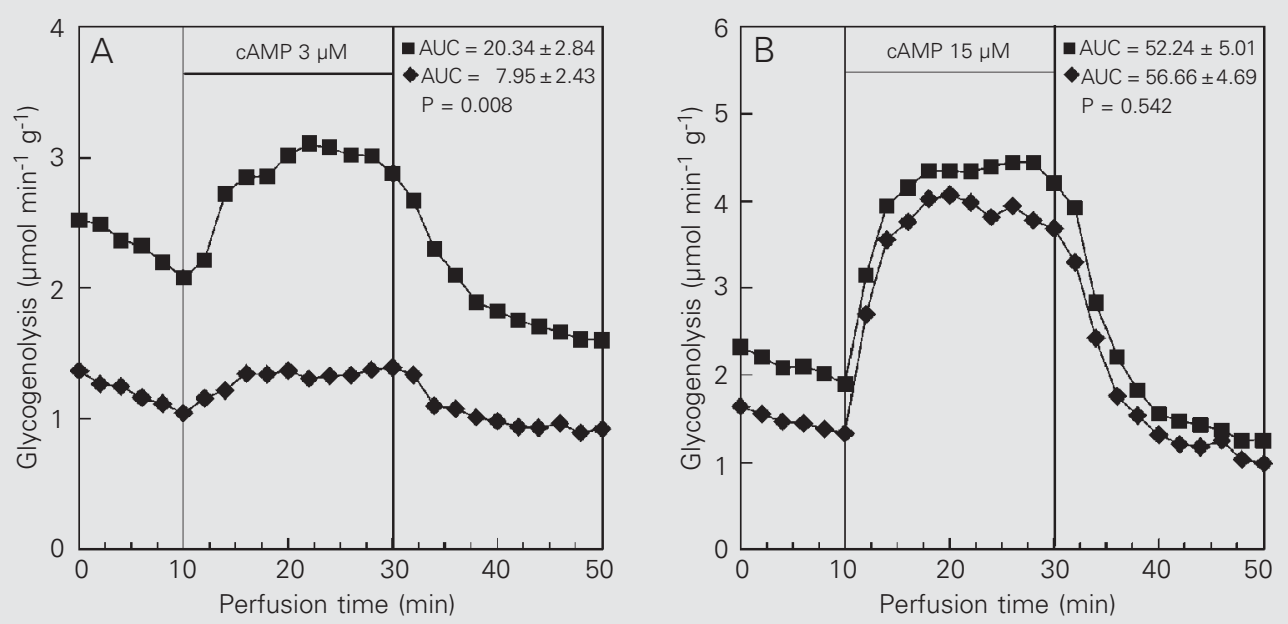

Figure 1. Effect of adenosine3'-5'-cyclic monophosphate (cAMP) (panels $A$ and $B$ ) and dibutyryl cAMP (DB-cAMP) (panels $C$ and $D$ ) on glycogenolysis. The data are reported as the means of 4-6 perfused livers obtained from rats killed $60 \mathrm{~min}$ after the injection of saline (control, squares) or insulin $(1 \mathrm{lU} / \mathrm{kg}$, lozenges). The area under the curve (AUC) data $(\mu \mathrm{mol} / \mathrm{g}$ liver fresh weight \pm SEM) are presented in the figure. The statistical test used was the unpaired Student $t$-test.
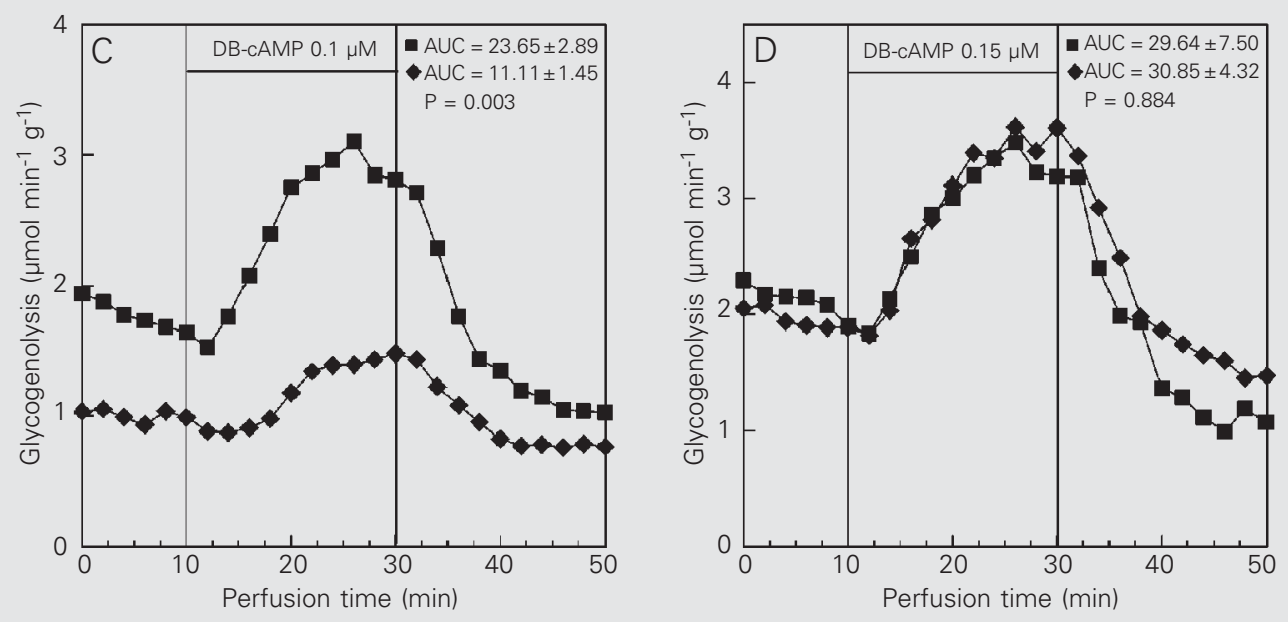
Figure 2. Effect of insulin on the activation of glycogenolysis promoted by adenosine- $3^{\prime}-5$ '-cyclic monophosphate (cAMP). The data are reported as the means \pm SEM of 4 experiments. The areas under the curve $(\mu \mathrm{mol} / \mathrm{g}$ liver fresh weight \pm SEM) during the infusion of $3 \mu \mathrm{M}$ cAMP (10$25 \mathrm{~min}$ ) and $3 \mu \mathrm{M}$ cAMP +500 $\mu \mathrm{lU} / \mathrm{ml}$ insulin $(25-35 \mathrm{~min}$ ) were $12.81 \pm 2.45$ and $4.88 \pm 1.51$, respectively. The statistical test used was the unpaired Student $t$-test and the $P$ value obtained was 0.033 .

Figure 3. Effect of adenosine-3'5 '-cyclic monophosphate (cAMP) (panels $A$ and $B$ ) and dibutyryl cyclic AMP (DB-cAMP) (panels C and $D$ ) on glycogenolysis in the presence (lozenges) and absence (squares) of insulin (500 $\mu \mathrm{lU} / \mathrm{ml})$. The data are reported as the means of 4-6 individual liver perfusion experiments. The area under the curve $(A \cup C)$ data $(\mu \mathrm{mol} / \mathrm{g}$ liver fresh weight \pm SEM) are presented in the figure. The statistical test used was the unpaired Student $t$-test.

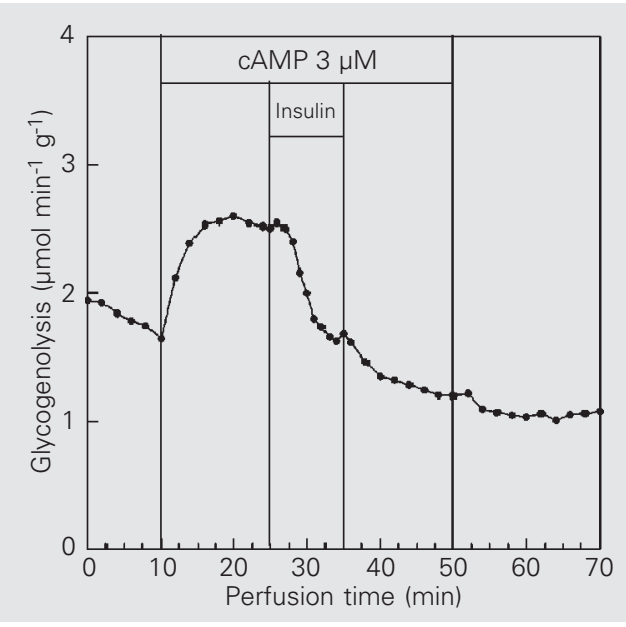

promoted by cAMP $(15 \mu \mathrm{M})$ and DB-cAMP $(0.15 \mu \mathrm{M})$ in the control and insulin groups was not different (Figure 1B,D).

Because insulin showed a direct effect on the activation of glycogen catabolism promoted by cAMP (Figure 2), we assessed the effect of insulin perfusion on glycogen catabolism promoted by cAMP and analogues (DB-cAMP, 8Br-cAMP, 6MB-cAMP). As shown in Figure 3, activation of hepatic glycogenolysis with cAMP (3 and $15 \mu \mathrm{M})$ and DB-cAMP $(0.1$ and $0.15 \mu \mathrm{M})$ was significantly reduced $(\mathrm{P}<0.05)$ when insulin was present in the perfusion fluid (Figure 3 ).
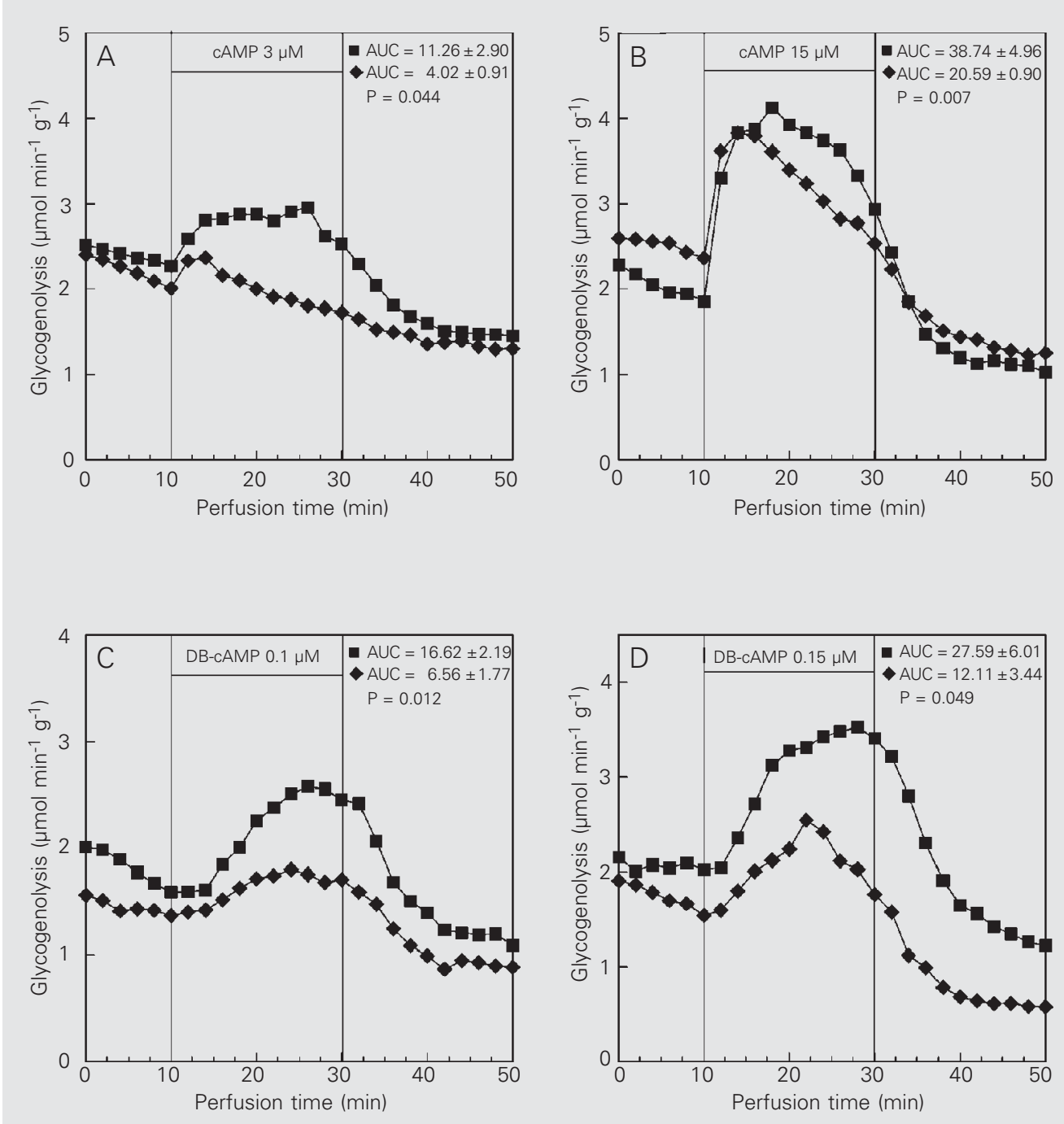
In contrast, the increase of glycogenolysis promoted by $3 \mu \mathrm{M} 8 \mathrm{Br}$-cAMP (Figure 4A) or $3 \mu \mathrm{M}$ 6MB-cAMP (Figure $4 \mathrm{~B}$ ) was not influenced by the presence of insulin.

\section{Discussion}

Hepatic glycogen breakdown in the liver is regulated in an opposite manner by insulin and cAMP-elevating agents. Recent studies from our laboratory have shown decreased responsiveness of glycogen breakdown to isoproterenol in livers from rats with insulininduced hypoglycemia (6). Because postreceptor mechanisms mediated by cAMP are important to activate hepatic glycogenolysis during insulin-induced hypoglycemia, we investigated this second messenger. Thus, by using CAMP and DB-cAMP at levels that produce about $50 \%$ of the maximal effect on glycogen catabolism ( 3 and $0.10 \mu \mathrm{M}$, respectively), we found a decreased hepatic responsiveness of glycogen catabolism during insulin-induced hypoglycemia (Figure 1A,C). However, no difference (Figure 1B,D) was observed when the concentrations of cAMP and DB-cAMP which produce the maximal glycogen catabolism were employed (15 and $0.15 \mu \mathrm{M}$, respectively).

To overcome the influence of counterregulatory factors which might have been released during insulin-induced hypoglycemia we examined the direct effect of insulin on hepatic glycogenolysis promoted by cAMP $(3 \mu \mathrm{M})$. As shown in Figure 2, insulin decreased $(\mathrm{P}<0.05)$ the hepatic responsiveness to cAMP, with the effect occurring as early as $3 \mathrm{~min}$ after the beginning of insulin infusion.

Since insulin showed a direct effect on hepatic responsiveness to cAMP we decided to study the direct effect of insulin on glycogenolysis promoted by cAMP and DB-cAMP at the concentrations used in the first set of experiments. Thus, in contrast to insulin rats, we observed decreased activation of glycogenolysis (Figure 3) not only with $3 \mu \mathrm{M}$ cAMP or $0.1 \mu \mathrm{M}$ DB-cAMP but also with 15 $\mu \mathrm{M}$ cAMP or $0.15 \mu \mathrm{M}$ DB-cAMP. Thus, the direct effect of insulin was more intense than that observed in the livers from rats with insulin-induced hypoglycemia (Figure 1).

The direct effect of insulin on the activation of glycogen catabolism promoted by 15 $\mu \mathrm{M}$ cAMP or $0.1 \mu \mathrm{M}$ DB-cAMP can be obtained with $0.3 \mu \mathrm{M}$ 8Br-cAMP (data not shown). Since $8 \mathrm{Br}$-cAMP is more resistant than cAMP to hydrolysis by phosphodiesterases, it is possible to overcome the influence of these enzymes by employing higher concentrations of $8 \mathrm{Br}-\mathrm{cAMP}$. Therefore, for comparison with the results obtained with 3
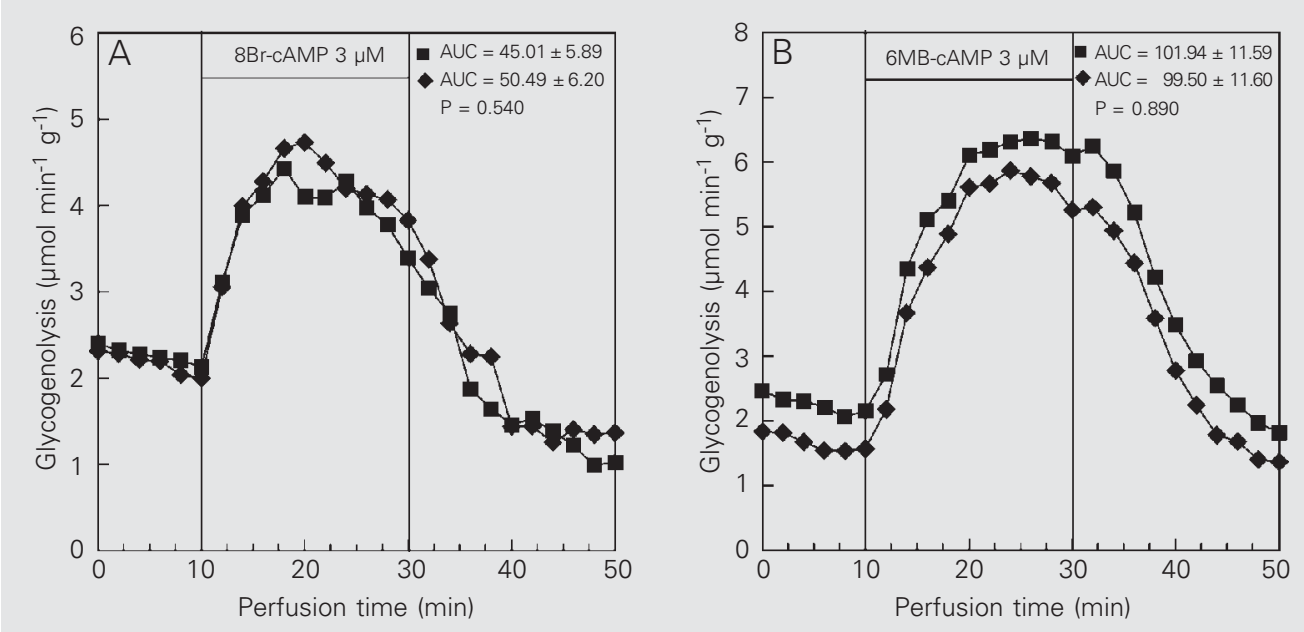

Figure 4. Effect of 8-bromoadenosine-3'-5'-cyclic monophosphate (8Br-cAMP) (panel A) or $\mathrm{N}^{6}$-monobutyryladenosine-3'5 '-cyclic monophosphate (6MBcAMP) (panel B) on glycogenolysis in the presence (lozenges) and absence (squares) of insulin $(500 \mu \mathrm{lU} / \mathrm{ml})$. The data are reported as the mean of 3-5 individual liver perfusion experiments. The area under the curve (AUC) data $(\mu \mathrm{mol} / \mathrm{g}$ liver fresh weight \pm SEM) are presented in the figure. The statistical test used was the unpaired Student t-test. 
$\mu \mathrm{M}$ cAMP we employed $3 \mu \mathrm{M}$ 8Br-cAMP.

In view of the fact that the activation of glycogen catabolism promoted by $3 \mu \mathrm{M} 8 \mathrm{Br}-$ cAMP was not influenced by insulin infusion (Figure 4A) and considering that this cAMP analogue operates as a protein kinase agonist (16), we may suggest that insulin affects the amount of cAMP in the liver.

Whereas $8 \mathrm{Br}$-cAMP is susceptible to hydrolysis by phosphodiesterase 3B, 6MBcAMP is resistant to hydrolysis by this enzyme due to the covalent modification at the $\mathrm{N}^{6}$ position (17). Thus, using 6MB-cAMP at a concentration which permits comparison with cAMP and 8Br-cAMP (i.e., $3 \mu \mathrm{M}$ ), we observed that the activation of glycogen catabolism promoted by $3 \mu \mathrm{M}$ 6MB-cAMP was not influenced by insulin infusion (Figure 4B). Consequently, the direct effect of insulin appears to be mediated mainly by the phosphodiesterase present in the liver, i.e., phosphodiesterase 3B.

Recently we reported that the decreased hepatic responsiveness to isoproterenol occurred at least 30 min after insulin administration (1). In contrast, we show here that the direct effect of insulin on hepatic responsiveness to cAMP occurred as early as $3 \mathrm{~min}$ after the beginning of insulin infusion (Figure 2). Since insulin acutely decreases the activation of glycogenolysis promoted by cAMP, this suggests the activation of phosphodiesterase 3B (18) and inhibition of adenylate cyclase (19).

Thus, our previous report (1) and the results obtained here suggest that the decreased hepatic responsiveness to isoproterenol is mediated not only by the adrenergic desensitization promoted by the release of catecholamines during insulin-induced hypoglycemia $(6,20)$, but also by a direct effect of insulin decreasing the cellular levels of cAMP. Additionally, we suggest that both mechanisms operated simultaneously in the liver, but that the decreased responsiveness of glycogenolysis mediated by insulin occurred prior to the adrenergic desensitization mediated by catecholamines released during insulin-induced hypoglycemia.

\section{Acknowledgments}

The authors are grateful to Mr. Carlos Eduardo de Oliveira and Solidalva Caruso de Oliveira for skillful technical assistance.

\section{References}

1. Vardanega-Peicher M, Lopes G, Lima FB, Curi R, Nakano LC \& Bazotte RB (2000). Time sequence of changes in the responsiveness of glycogen breakdown to adrenergic agonists in perfused liver of rats with insulin-induced hypoglycemia. Brazilian Journal of Medical and Biological Research, 33: 805-813.

2. Moore MC, Connolly CC \& Cherrington AD (1998). Autoregulation of hepatic glucose production. European Journal of Endocrinology, 138: $40-48$.

3. Souza HM, Borba-Murad GR, Ceddia RB, Curi R, Vardanega-Peicher $M$ \& Bazotte RB (2001). Rat liver responsiveness to gluconeogenic substrates during insulin-induced hypoglycemia. Brazilian Journal of Medical and Biological Research, 34: 771-777.

4. Jackson PA, Cardin S, Coffey CS, Neal DW, Allen EJ, Penaloza AR, Snead WL \& Cherrington AD (2000). Effect of hepatic denervation on the counterregulatory response to insulin-induced hypoglycemia in the dog. American Journal of Physiology, 279: E1249-E1257.

5. Heptulla RA, Tamborlane WV, Ma TY, Rife F \& Sherwin RS (2001). Oral glucose augments the counterregulatory hormone response during insulin-induced hypoglycemia in humans. Journal of Clinical
Endocrinology and Metabolism, 86: 645-648

6. Lopes G, Lima FB, Hell NS, Vardanega M \& Bazotte RB (1998). The responsiveness of glycogen catabolism to adrenergic agonists during insulin-induced hypoglycemia $(\mathrm{IIH})$ in rat livers. General Pharmacology, 30: 593-599.

7. Vicentini GE, Constantin J, Lopez CE \& Bracht A (2000). Transport of cyclic AMP and synthetic analogs in the perfused rat liver. Biochemical Pharmacology, 59: 1187-1201.

8. Bazotte RB, Constantin J, Curi R, Kemmelmeier FS, Hell NS \& Bracht A (1989). The sensitivity of glycogenolysis to glucagon, epinephrine and cyanide in livers from rats in different metabolic conditions. Research Communications in Chemical Pathology and Pharmacology, 64: 193-205.

9. Bazotte RB, Pereira B, Highan S, Shoshan-Barmatz V \& KrausFriedmann N (1991). Effects of ryanodine on calcium sequestration in the rat liver. Biochemical Pharmacology, 42: 1799-1803.

10. Bergmeyer HU \& Bernt E (1974). Determination of glucose with glucose-oxidase and peroxidase. In: Bergmeyer HU (Editor), Methods of Enzymatic Analysis. Vol. 2. Academic Press, New York, NY, 
USA, 1205-1215.

11. Desbuquois B \& Aurbach GD (1971). Use of polyethyleneglycol to separate free and antibody-bound peptide hormones in radioimmunoassays. Journal of Clinical Endocrinology, 33: 732-738.

12. Ceddia RB, Lopes G, Souza HM, Borba-Murad GR, William Jr WN, Bazotte RB \& Curi R (1999). Acute effects of leptin on glucose metabolism of in situ rat perfused livers and isolated hepatocytes. International Journal of Obesity, 23: 1207-1212.

13. Czok R \& Lamprecht W (1974). Pyruvate, phosphoenolpyruvate and D-glycerate-2-phosphate. In: Bergmeyer HU (Editor), Methods of Enzymatic Analysis. Vol. 2. Academic Press, New York, NY, USA, 1446-1448.

14. Gutmann I \& Wahlefeld W (1974). L-(+)-Lactate. Determination with lactate dehydrogenase and NAD. In: Bergmeyer HU (Editor), Methods of Enzymatic Analysis. Vol. 2. Academic Press, New York, NY, USA, 1464-1472.

15. Kimmig R, Mauch TJ, Kerzl W, Schwabe U \& Scholz R (1983) Actions of glucagon on flux rates in perfused rat liver. 1. Kinetics of the inhibitory effect on glycolysis and the stimulatory effect on glycogenolysis. European Journal of Biochemistry, 136: 609-616.
16. Zhao $A Z$, Shinohara MM, Huang D, Shimizu M, Eldar-Finkelman $H$, Krebs EG, Beavo JA \& Bornfeldt KE (2000). Leptin induces insulinlike signaling that antagonizes CAMP elevation by glucagon in hepatocytes. Journal of Biological Chemistry, 15: 11348-11354.

17. Hermsdorf T \& Dettmer D (1998). Combined effects of insulin and dexamethasone on cyclic AMP phosphodiesterase 3 and glycogen metabolism in cultured rat hepatocytes. Cellular Signalling, 10: 629635.

18. Kitamura T, Kitamura Y, Kuroda S, Hino Y, Ando M, Kotani K, Konishi H, Matsuzaki H, Kikkawa U, Ogawa W \& Kasuga M (1999). Insulininduced phosphorylation and activation of cyclic nucleotide phosphodiesterase 3B by the serine-threonine kinase Akt. Molecular and Cellular Biology, 19: 6286-6296.

19. Irvine F, Wallace AV, Sarawak SR \& Houslay MD (1993). Extracellular calcium modulates insulin's action on enzymes controlling cyclic AMP metabolism in intact hepatocytes. Biochemical Journal, 264: 249-253.

20. Cryer P (1993). Glucose counterregulation: prevention and correction of hypoglycemia in humans. American Journal of Physiology, 264: E149-E155. 